\title{
Initial investigation of nutrition and supplement use, knowledge and attitudes of under-16 rugby players in South Africa
}

\author{
K M Duvenage, ${ }^{1}$ BSc (Dietetics); S T Meltzer, ${ }^{1,2}$ MSc (Med) (Nutr \& Dietetics); S A Chantler, ${ }^{1}$ MSc (Med) (Exerc Sci) \\ ${ }^{1}$ Shelly Meltzer and Associates, Cape Town, South Africa \\ ${ }^{2}$ Division of Human Nutrition, Department of Human Biology, University of Cape Town, South Africa
}

Corresponding author: K Duvenage (karliens@gmail.com)

\begin{abstract}
Background. Internationally young athletes are reported to have a poor understanding of the principles of sports nutrition and supplement use; hence their diet may be unhealthy and inappropriate for participation in sport. There is limited research on current nutritional knowledge and attitudes of under-16 (U16) age-group level rugby players in South Africa (SA).

Objectives. To assess dietary- and supplement-related knowledge and attitudes of 198 U16 national-level rugby players in SA.

Methods. Over a period of four consecutive years a total of 198 players attending nutrition workshops at the annual selection camp received and completed an anonymous structured questionnaire. Anthropometric measures (weight, height and skinfolds) were gathered by registered biokineticists.

Results. Of players $87 \%$ (168/193) indicated that they wanted to increase lean muscle mass, with $42 \%$ (82/194) feeling pressurised to do so by their coach and/or parents. Almost half (85/196) believed their diets to be poor. Players had better knowledge about nutrition recovery strategies than pre-game meals. Seventy per cent (136/195) identified optimal timing and 56\% (109/196) knew the ideal macronutrient composition of recovery meals. Over $60 \%$ of players believed supplements were safe (115/192) and necessary (132/193) for increasing muscle mass, and almost half (106/195) believed they could take creatine. Over a third (68/170) also believed that the protein quality of supplements was higher than that of food. Supplements were primarily recommended by coaches and non-dietetic medical practitioners. Eight of the players self-prescribed supplements and four were taking supplements on the advice of a store salesperson or representative. Conclusion. The elite U16 rugby players in this study lacked comprehensive sports nutritional knowledge, yet had an overly positive attitude toward supplementation and used supplements haphazardly to achieve body composition goals. Tailor-made nutrition interventions with a strong education component are recommended to improve players' nutritional knowledge, as well as access to registered dietitians working in sport to advise on supplements.
\end{abstract}

S Afr J Sports Med 2015;27(3):67-71. DOI:10.7196/SAJSM.8092

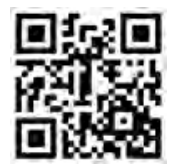

Internationally, young athletes, including schoolboy rugby players, are reported to have a poor understanding of the principles of sports nutrition and unwarranted supplement use; as a result their dietary behaviours may be unhealthy and inappropriate for their sport. ${ }^{[1]}$ The change in the level of professionalism of rugby has also had an effect on the younger age groups, by increasing the pressure for early muscle mass gains and strength, as within each age group heavier players seem to have a competitive advantage and are more likely to be selected for high-level teams. ${ }^{[2]}$ Since 1968 the average body mass of a Craven Week rugby player has increased by $10 \mathrm{~kg}(6.6 \%),{ }^{[2]}$ and the boys selected from this tournament for the South African (SA) Schools team are roughly $8 \mathrm{~kg}$ heavier than the average weight of boys who do not make the team. This weight increase can to a large extent be attributed to increases in resistance training as part of the regular training of this age group. ${ }^{[2]}$

The increased physiological and training demands for these younger players coincide with additional age-specific nutritional demands. These include consuming sufficient energy and nutrients for normal growth and development, maintaining adequate hydration, and ensuring appropriate timing and composition of meals for optimal performance and body composition. ${ }^{[3]}$ The current consensus internationally is that the optimal way to meet these age- and sport-specific demands is with a well-planned diet focusing on food and, if necessary, using supplements under the guidance of a qualified dietitian specialising in sport nutrition. Only where an expert health professional identifies a specific dietary gap may select supplementation be used in conjunction with dietary optimisation. ${ }^{[4]}$

Unfortunately, in spite of this consensus, there is limited evidence with regard to the sport-specific nutritional needs of adolescents compared to adults, and in addition little is known about the physiological and psychological effects of supplementation in the under-18 age group. ${ }^{[4,5]}$ The reality is that use of supplements by adolescent athletes is rife, and is of concern. ${ }^{[4]}$

In a KwaZulu-Natal-based study in SA, 54 - 55.5\% of rugby-playing school boys (age 16 - 17 years and under 13 years, respectively, $N=222$ ) reported using some form of supplementation. ${ }^{[5,6]}$ Moreover, the introduction and misuse of supplements may contribute to the increase in positive doping tests or steroid use in school-based sport, as well as an increase in other substance abuse (e.g. alcohol).$^{[7,8]}$ In a 2011 study on use of steroids in 20 rugby-playing schools (also in KwaZulu-Natal) it was found that $4.6 \%$ of the 9824 male respondents had used androgenic anabolic steroids, and $2.7 \%$ of males were currently using them (Hagemann G, 2014, personal communication). Nutritional supplements are often viewed as a 'safety net' by young athletes, because they lack the appropriate knowledge relating to the 
quantity and quality of their dietary intakes. ${ }^{[5]}$ A single rugby-specific questionnairebased study in Ireland showed nutrition knowledge (based on a composite score) to be poor among young rugby players (age 15 - 18 years). ${ }^{[1]}$ Other studies in adolescent athletes in other sports have shown a similar trend. ${ }^{[5,9-13]}$ In a recent SA study Varsity Cup players' (mean (standard deviation (SD) age 21.9 (1.2) years) habitual dietary intakes and match-day strategies were found to be suboptimal, and supplement use was high. ${ }^{[14]}$ In other studies supplement use has also been linked to pressure from coaches, peers, competitors and parents, ${ }^{[4,6]}$ often reinforced by unsubstantiated and exaggerated claims made by an industry which is practically unregulated. ${ }^{[4]}$

Rugby is one of the major team sports in SA, with a total of 633299 rugby players registered in the country in 2013, and a following of around 10 million. ${ }^{[9]}$ Of the registered players, $82 \%$ are preteens and teens. ${ }^{[9]}$ The culture formed at school level can be taken through to higher-level rugby, making this group of athletes a large target for possible research and nutritional intervention. Currently there are no published studies on the knowledge, attitudes and practices of nutrition and use of supplements among elite/high-level adolescent rugby players in SA. This is an important area to study as intervention studies have previously shown that better knowledge can positively effect nutritional practices. ${ }^{[13]}$

The objective of this study was to investigate the nutrition knowledge, basic attitudes and supplement use of four different groups of national-level under-16 (U16) rugby players over 4 consecutive years.

\section{Methods}

\section{Subjects and questionnaire}

In July of every year in SA a national selection panel identifies the top $50 \mathrm{U} 16$ players at Grant Khomo Week, which is the national U16 tournament. The top 50 players then attend a camp in the school holidays and receive specialist training in their positions as well as in life skills, technical aspects of coaching, conditioning, nutrition and mental preparation.

During this camp, over a period of 4 consecutive years $(2009,2010,2011$ and 2012), a total of 198 male players attended the workshop and were given a dietary questionnaire specifically designed for this study. The questionnaire was designed as a pre-workshop investigation by targeting basic ideas and concepts with a low responder burden. Many of the questions were similar to those asked in standard dietary consultations with this age group. The questionnaire had been proofread and tested by an expert external panel of non-dietetic staff members of the University of Cape Town and the Sports Science Institute of SA (SSISA). The questionnaire comprised four sections with 18 questions in total. The overall design of the questionnaire is displayed in Table 1.

At the start of the dietary workshops the questionnaires were handed out and completed by the players, before they received any nutrition information. The players completed the questionnaires in the presence of at least one dietitian with sports nutrition experience to help with questions, and other staff members of the team to ensure minimal peer influences between participants. They were assured that all information gathered would be confidential and no names were recorded on the questionnaire; results would not be shared with coaches or trainers, and only participant numbers would appear on questionnaires.

Anthropometric data were gathered by registered and trained biokineticists (of the Discovery High Performance Centre at SSISA). It was therefore expected that the inter-rater variability would be relatively low.

\section{Table 1. Design of the questionnaire}

Section A:
Mainly open-ended questions:
Weight, height, age, self-reported
position of play
Body composition goals
Section C:
Four-point Likert scale:
Attitude and beliefs towards their own
diets and supplements

\section{Section B:}

Multiple-choice questions:

Knowledge of basic nutrition with regard to weight management, prematch nutrition, recovery nutrition

Section D:

Open-ended questions:

Supplement use

Dosages

Who recommended

Table 2. Mean (SD) weight, height and body fat of participants over the 4 years of the study

\begin{tabular}{lllll}
\hline & $\mathbf{2 0 0 9}(\boldsymbol{N}=\mathbf{4 9})$ & $\mathbf{2 0 1 0}(\mathbf{N = 4 9 )}$ & $\mathbf{2 0 1 1}(\boldsymbol{N}=\mathbf{5 0})$ & $\mathbf{2 0 1 2}(\boldsymbol{N = 5 1 )}$ \\
\hline Weight $(\mathrm{kg})$ & $84.9(11.4)$ & $85.7(15.0)$ & $86.4(14.2)$ & $86.2(15.0)$ \\
Height $(\mathrm{cm})$ & $179.2(7.8)$ & $177.3(14.1)$ & $180.6(8.8)$ & $179.2(7.8)$ \\
Body fat $(\%)$ & $18.9(3.9)$ & $20.3(4.3)$ & $18.9(4.3)$ & $19.6(4.3)$
\end{tabular}


As some participants left some questions blank, the $N$-value was adjusted for the each question. Parametric data are presented as mean (SD). Analysis of variance measures were used to compare anthropometry between groups (forwards/backs) and years (4 years). Frequencies of knowledge, attitude and practices regarding nutrition and supplementation were compared using $\chi^{2}$ tests. Statistical significance was based on a $p$-value of $<0.05$, and all data were analysed using STATISTICA version 10 (StatSoft Inc., USA).

\section{Results}

Table 2 presents the mean (SD) weight, height and body fat of the participants over the 4 years. During this time average weight ranged from 84.9 (11.4) kg to $86.4(14.2) \mathrm{kg}$, height ranged from $177.3(14.1) \mathrm{cm}$ to $180.6(8.9) \mathrm{cm}$, and body fat ranged from $18.9 \%$ (3.9\%) to $20.3 \%$ (4.3\%). There were no significant differences from year to year with regard to mean weight, height or body fat percentage.

The mean weight and height of the players were above the 50th percentile for their age according to the $\mathrm{WHO}^{[15]}$ and in accordance with norms for their age and level according to Boksmart. ${ }^{[2]}$ The mean body fat percentage was slightly above the norm, but was not position specific. ${ }^{[17]}$

\section{Body composition goals}

Eighty seven per cent of the players (168/193) indicated that they wanted to increase lean muscle mass.

\section{Basic nutritional knowledge}

The most frequent answers by participants to the nutritional knowledge questions are presented in Table 3. Although there was slight annual variation, there was no significant difference between the years.

\section{Attitudes and beliefs towards diet and supplements}

The questions regarding dietary attitudes and beliefs had responses on a standard Likert scale. Table 4 presents the frequency of those who 'Agreed' or 'Strongly agreed' with the statement given. Forty three per cent of the participants agreed that they had a poor diet, while the majority (68\%) agreed that they needed a protein supplement to gain muscle mass, which almost half of them (42\%) felt pressurised to do. Although most of the participants $(66 \%)$ did not agree that they needed supplements to perform at their peak, the majority $(60 \%)$ indicated that taking supplements would not result in a positive doping test and that they could take creatine at their age (54\%).

\section{Supplement use}

Over the 4-year period 84 (42\%) of the players reported that they were taking at least one supplement, with two players taking as many as five different supplements simultaneously (Fig. 1). Dosages and frequency were not provided.

Protein supplements were the most prevalent supplement used (31\%). There was no statistically significant difference in supplement use over the course of each year. Table 5 shows a summary of who recommended the use of the supplement.

Table 3. Nutritional knowledge by highest frequency answer of the participants by year

\begin{tabular}{|c|c|c|c|c|c|}
\hline \multirow[b]{2}{*}{ Question } & \multicolumn{5}{|c|}{ Answer with highest score, $\%(n / N)$} \\
\hline & 2009 & 2010 & 2011 & 2012 & Average $^{\star}$ \\
\hline $\begin{array}{l}\text { Most ideal strategy to avoid } \\
\text { gaining fat mass }\end{array}$ & $\begin{array}{l}\text { Cut out all sugar } \\
-38(18 / 48)\end{array}$ & $\begin{array}{l}\text { Eat a low-fat, } \\
\text { balanced diet }-46 \\
(22 / 48)\end{array}$ & $\begin{array}{l}\text { Eat a low-fat, } \\
\text { balanced diet - } 40 \\
(19 / 47)\end{array}$ & $\begin{array}{l}\text { Eat a low-fat, balanced } \\
\text { diet - } 29 \text {; eat more } \\
\text { protein - } 29(14 / 48)\end{array}$ & $\begin{array}{l}\text { Eat a low-fat, } \\
\text { balanced diet }-37 \\
(n=191)\end{array}$ \\
\hline $\begin{array}{l}\text { Best meal to have the night } \\
\text { before a match }\end{array}$ & $\begin{array}{l}\text { Creamy pasta } \\
\text { Alfredo }-83 \\
(40 / 48)\end{array}$ & $\begin{array}{l}\text { Creamy pasta } \\
\text { Alfredo }-68 \\
(34 / 50)\end{array}$ & $\begin{array}{l}\text { Creamy pasta } \\
\text { Alfredo }-69 \\
(33 / 48)\end{array}$ & $\begin{array}{l}\text { Creamy pasta Alfredo } \\
-62(31 / 50)\end{array}$ & $\begin{array}{l}\text { Creamy pasta } \\
\text { Alfredo }-70 \\
(n=196)\end{array}$ \\
\hline $\begin{array}{l}\text { Optimum time for a recovery } \\
\text { meal }\end{array}$ & $\begin{array}{l}30-40 \min -67 \\
(32 / 48)\end{array}$ & $\begin{array}{l}30-40 \min -73 \\
(36 / 49)\end{array}$ & $\begin{array}{l}30-40 \min -69 \\
(33 / 48)\end{array}$ & $\begin{array}{l}30-40 \min -70 \\
(35 / 70)\end{array}$ & $\begin{array}{l}30-40 \min -70 \\
(n=195)\end{array}$ \\
\hline $\begin{array}{l}\text { What ideal recovery snack } \\
\text { should contain }\end{array}$ & $\begin{array}{l}\text { Protein and } \\
\text { carbohydrate }-51 \\
(24 / 47)\end{array}$ & $\begin{array}{l}\text { Protein and } \\
\text { carbohydrate }-51 \\
(26 / 51)\end{array}$ & $\begin{array}{l}\text { Protein and } \\
\text { carbohydrate }-60 \\
(29 / 48)\end{array}$ & $\begin{array}{l}\text { Protein and } \\
\text { carbohydrate }-60 \\
(30 / 50)\end{array}$ & $\begin{array}{l}\text { Protein and } \\
\text { carbohydrate }-56 \\
(n=196)\end{array}$ \\
\hline
\end{tabular}

Table 4. Attitudes and beliefs about diet, muscle mass, protein and supplements, \% $(n / N)$

\begin{tabular}{|c|c|c|c|c|c|}
\hline & 2009 & 2010 & 2011 & 2012 & Average $^{*}$ \\
\hline I rate my diet as poor or very poor & $49(23 / 47)$ & $33(16 / 49)$ & $50(25 / 50)$ & $42(21 / 50)$ & $43(85 / 196)$ \\
\hline I feel pressurised by my coach and/or parents to increase my lean body mass & $48(22 / 46)$ & $43(21 / 49)$ & $37(18 / 49)$ & $42(21 / 50)$ & $42(82 / 194)$ \\
\hline $\begin{array}{l}\text { I believe that I would have to take a protein supplement to increase } \\
\text { muscle mass }\end{array}$ & $70(32 / 46)$ & $72(36 / 50)$ & $68(32 / 47)$ & $64(32 / 50)$ & $68(132 / 193)$ \\
\hline I believe the quality of protein in a supplement is higher than that of food & $47(18 / 38)$ & $42(18 / 42)$ & $22(9 / 41)$ & $48(23 / 48)$ & $40(68 / 170)$ \\
\hline I need a supplement to perform at my peak & $30(14 / 47)$ & $48(24 / 50)$ & $22(11 / 49)$ & $37(18 / 49)$ & $34(67 / 195)$ \\
\hline I don't think that taking a supplement can lead to a positive doping test & $65(31 / 48)$ & $63(31 / 49)$ & $48(22 / 46)$ & $63(31 / 49)$ & $60(115 / 192)$ \\
\hline I believe I can take creatine & $50(24 / 48)$ & $55(27 / 49)$ & $60(29 / 48)$ & $52(26 / 50)$ & $54(106 / 195)$ \\
\hline
\end{tabular}




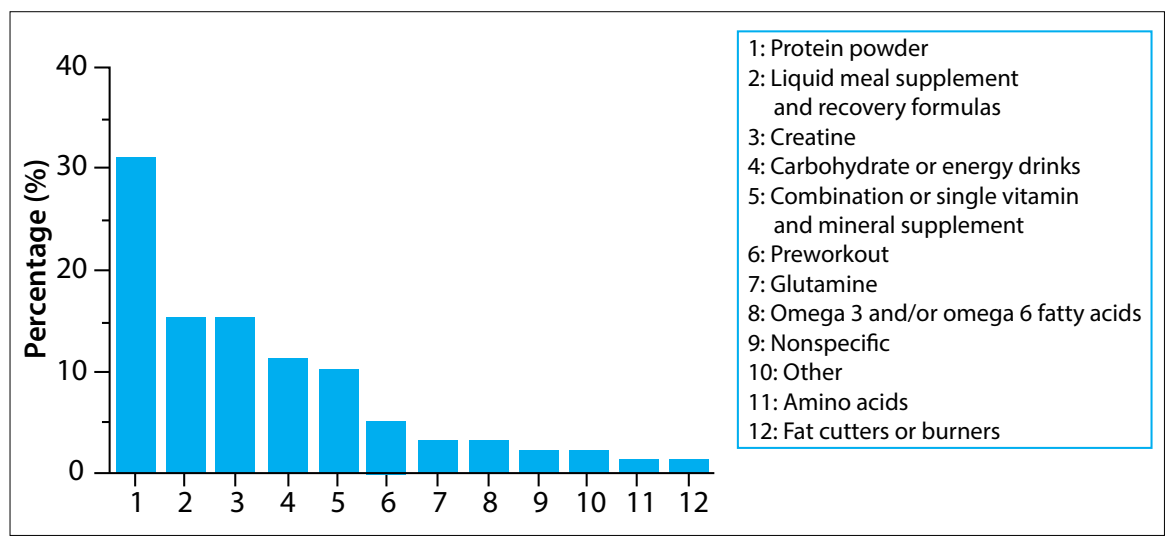

Fig. 1. Types of supplements and prevalence (\%) reported by players $(\mathrm{n}=150)$.

Table 5. Who recommended the use of supplements

\begin{tabular}{ll}
\hline Supplement advisor & Players $(\mathbf{N}=\mathbf{8 4}), \boldsymbol{n} \mathbf{( \% )}$ \\
\hline $\begin{array}{l}\text { Non-nutritional medical staff (general practitioner, physiotherapist, } \\
\text { pharmacist, or biokineticist) }\end{array}$ & $19(22)$ \\
Coaches, rugby unions, other rugby teams & $17(20)$ \\
Self & $8(10)$ \\
Gym instructor or gym & $6(6)$ \\
Family and friends & $8(5)$ \\
Supplement representative or store & $4(5)$ \\
Dietitian & $2(2)$
\end{tabular}

\section{Discussion}

In this descriptive survey of elite U16 SA rugby players it was evident that while the participants had better knowledge about recovery strategies than other general nutritional practices for athletes, their attitudes demonstrated a desire to increase lean muscle mass without the appropriate nutritional knowledge to do so. It was also evident that the perceived pressure to increase lean mass was from external sources. This pressure may have contributed to nearly half of these adolescents taking one or more dietary supplements, believing these to be safe and necessary for increasing muscle mass, while many believed their diets were poor. Of further concern is the lack of professional specialised nutritional advice given to this age group.

The players had a mean body weight of 85.8 (13.9) kg, with the expected differences found between forwards and back-line players. When related to the WHO growth charts, they were above the 50th percentile for their age-appropriate weight and height. This is expected due to their sport and level of play. However, when compared with available SA need for food-based nutritional interventions, as the relationship between dietary education and a positive effect on knowledge has been highlighted in other intervention studies. ${ }^{[1,13]}$

Resorting to supplements as a means to build muscle mass rather than improving their diets is problematic. Although most players did not believe that supplements were required for peak performance, it is of concern that $68 \%$ believed that protein supplements were required for increasing muscle mass and almost half of the players believed that they could take creatine. This despite the fact that the international consensus on creatine use suggests that it should be limited to experienced and well-matured athletes, because it may lead to increased injuries and have a gateway effect. ${ }^{[4,5]}$

Several international studies ${ }^{[4-6,10-13]}$ of both elite and school-level adolescents in Western countries have indicated that supplements are commonly used, particularly by athletes who do weight training. In international research the type of supplements most commonly used varied somewhat depending on the study, but included multivitamins and single-nutrient supplements, e.g. vitamin C, protein powders, amino acids, creatine and sport drinks, which is similar to what was found in our study. ${ }^{[6,12]} \mathrm{A}$ notable difference is that in our study we found that pre-workout supplements and fat-cutters were also being used.

As has been found previously, ${ }^{[5,6]}$ supplements were primarily recommended by coaches and medical practitioners (other than dietitians). This is of concern as a dietitian is uniquely qualified to assess each player's diet and to make recommendations accordingly. ${ }^{[4]}$ The process of prescribing a supplement is an intensive one that requires an understanding of each player's habitual diet, medical history, lifestyle, access to food and training programme and periodisation. A dietitian can recommend the appropriate dietary principles to prevent deficiencies and optimise performance through a 'food first' approach and, if warranted, prescribe a supplement to be integrated into the overall nutrition plan. ${ }^{[3,4]}$

Given the current supplementation and doping climate, it is alarming that the majority of boys did not think there were risks involved in supplement use, nor did they consult specialised health professionals for advice. Of further concern is the evidence that supplements are being used despite the lack of long-term safety data, and without dietary-intake assessment to determine if 
supplementation is required. Over a third (40\%) of the players also seemed to believe that the protein quality in supplements is higher than that of food. This has also been evident in American high school football and volleyball players ${ }^{[10]}$ and high-school athletes. ${ }^{[18]}$

In terms of risk management, the 'food first' approach is becoming the international norm, supported by a best practice supplement protocol managed and directed by the team dietitian. ${ }^{[3,4,19]}$ The Australian rugby model ${ }^{[19]}$ is a superb example of such a systematic best-practice approach. Buy-in to a national system like this would give professional players at all levels confidence in the system, as they would have an avenue where they know they can ask for reliable information. Ultimately this system could filter down through the age groups to create a culture of positive nutritional choices with strategic supplement use.

This approach would have merit in SA, as in our study it was alarming to see that $10 \%$ of players self-prescribed supplements, with $5 \%$ taking supplements on the advice of a store salesperson or representative. Young athletes are often easily influenced by strong marketing strategies, ${ }^{[4,5]}$ yet there is limited evidence to show efficacy and safety of sport supplements in adolescents. ${ }^{[4,5,18]}$ Of course another concern is the gateway theory linking the regular use of supplements to alcohol, marijuana and androgenic anabolic steroids among college students. ${ }^{[7,8]}$ This is exacerbated by the lack of regulation within the marketing and production of supplements, aggressive marketing and the high risk of contamination. ${ }^{[4,5]}$

\section{Study limitations}

In the present study an observational questionnaire in a relatively small but elite sample was used, and thus the generalisation of results is limited. However, the findings do give some important insights into the nutrition and supplement habits of players in this age group. Ideally the questionnaire should be validated further in a larger sample, with focus groups to capture qualitative data, and the same participants should be reassessed at a follow-up session to see if their knowledge on nutrition and supplement use improved.

\section{Conclusion}

The elite U16 rugby players participating in this study lacked solid sports nutritional knowledge and were using supplements haphazardly to achieve goals. This is out of date with international best practice nutrition and supplement approaches. For example, Australia has introduced a comprehensive Sports Supplement Policy, ${ }^{[18]}$ which acknowledges the use of supplements but only if used appropriately and supported by a nutritional programme to ensure player health and safety. This has been adapted by some sports federations, including the Australian Rugby Union (ARU), which has established a Supplement Advisory Group ${ }^{[19]}$ to ensure strict measures with regard to supplement use, and decreed that all Australian national teams and super-rugby clubs appoint a fully qualified and accredited Sports Dietitian who is responsible for overseeing the provision of supplements at the club. Players need prior consent from their Team Sports Dietitian and written approval from the ARU Supplement Advisory Group for use of any supplement which has not been preapproved. All supplement use by clubs and players is detailed on a centrally documented system. Another key feature of the programme is improved player education. ${ }^{[19]}$

This model should be investigated to see how it could be adapted to our local environment. The importance of education and research as key focus areas is evident. Clubs and players should be encouraged to engage the services of a registered dietitian working in sport to improve dietary knowledge and practices, as well as when considering taking a supplement. Education focusing on the positive role of good nutrition and supplements should be extended to general practitioners and support staff.

Coaches specifically need to be involved and to promote the same message, as they are known to be the greatest influence on supplement choices. ${ }^{[5]}$ It goes without saying that proactive research programmes are essential to evolve best practice protocols.

Acknowledgements. We thank the SA Rugby Union and the Discovery High Performance Centre at the SSISA for their assistance and support in this project.

\section{References}

1. Walsh M, Cartwright L, Corish C, Sugrue S, Wood-Martin R. The body composition nutritional knowledge, attitudes, behaviors, and future education needs of senior schoolboy rugbyplayers in Ireland. Int J Sport Nutr Exerc Metab 2011;21(5):365-376

2. Lambert M, Forbes J, Brown J. SA Rugby Boksmart: Age vs weight category Rugby, 2010. www.sarugby.co.za/boksmart/pdf/BokSmart\%202010-Age\%20vs\%20 Weight\%20Category\%20Rugby.pdf (accessed 3 September 2014).

3. Lanham-New SA, Stear SJ, Shirreffs SM, Collins AL. Sport and Exercise Nutrition. 1st ed. Oxford: Wiley-Blackwell, 2011:316-322.

4. South African Institute of Drug Free Sport. Position Statement of the South African Institute of Drug Free Sport (SAIDS) on the use of supplements in sport in schoolgoing youth, 2011. http://www.sasma.org.za/articles/SAIDS\%20Position $\% 20$ Statement\%20for\%20YOUTH.pdf (accessed 3 September 2014).

5. Strachan K. Current perceptions and usage practices of nutritional supplements amongst adolescent rugby-playing school boys from the KwaZulu-Natal region. Masters in Nutrition thesis. Stellenbosch University, 2009.

6. Steenkamp A, Meltzer S, Harbron J, Readhead C. The use of dietary supplements in South African rugby players participating in the under 13 Coca-Cola Craven week tournament. BMed Sci Hons (Nutrition and Dietetics) thesis. Faculty of Health Sciences, University of Cape Town, 2013.

7. Buckman JF, Yusko DA, White HR, Pandina RJ. Risk profile of male college athletes who use performance-enhancing substances. J Stud Alcohol Drugs 2009;70(6):919-923.

8. Hildebrandt T, Harty S, Langenbucher JW. Fitness supplements as a gateway substance for anabolic-androgenic steroid use. Psychol Addict Behav 2012;26(4):955-962. [http://dx.doi.org/10.1037/a0027877]

9. South African Rugby Union. South African Rugby Union Annual Report 2012. http://images.supersport.co.za/SARU\%20Annual\%20Report\%202010.pdf (accessed 30 September 2014).

10. Mason MA, Giza M, Clayton L, Lonning J, Wilkerson RD. Use of nutritional supplements by high school football and volleyball players. Iowa Orthop J 2001;21:43-48.

11. Nieper A. Nutritional supplement practices in UK junior national track and field athletes. Br J Sports Med 2005;39:645-649. [http://dx.doi.org/10.1136/bjsm.2004.015842]

12. McDowall JA. Supplement use by young athletes. Review article. J Sports Sci Med 2007;6:337-342.

13. Massad SJ, Shier NW, Koceja DM, Ellis NT. High school athletes and nutritional supplements: A study of knowledge and use. Int J Sport Nutr 1995;5(3):232-245.

14. Potgieter S, Visser J, Croukamp I, Markides M, Nascimento J, Scott K. Body composition and habitual and match-day dietary intake of FNB Maties Varsity Cup rugby players. $S$ Afr J Sports Med 2014;26(2):35-43. [http://dx.doi.org/10.7196/SAJSM.504]

15. World Health Organization. The WHO Child Growth Standards. http://www.who.int/ childgrowth/standards/en/ (accessed 18 February 2014)

16. Durandt J, du Toit S, Borresen J, et al. Fitness and body composition profiling of elite junior South African rugby players. S Afr J Sports Med 2006;18(2):38-45.

17. Duellman MC, Lukaszuk JM, Prawitz AD, Brandenburg JP. Protein supplement users among high school athletes have misconceptions about effectiveness. J Strength Cond Res 2008;22(4):1124-1129. [[http://dx.doi.org/10.1519/JSC.0b013e31817394b9]

18. Australian Rugby Union Limited. Sports supplement policy, effective from 17 February 2014. http://www.rugby.com.au/Portals/1/PDFs/Administration/Sport\%20Supliments\%20 Policy/20140610_ARUSportsSupplementsPolicy.pdf (accessed 1 September 2014).

19. Australian Institute of Sport. AIS Sports Supplement Framework. http://www.ausport. gov.au/ais/nutrition/supplements (accessed 9 March 2015). 